\title{
Removal of Maxlion Blue GRL Dye over Powdered Limestone Surface
}

\author{
Hussein A. Esmael \\ Babylon University, Chemistry Department, Babylon, HILLA, Iraq, 51002
}

\begin{abstract}
The present study describes adsorption of maxlion blue GRL dye (MBGRL) over the surface of limestone using simulated aqueous solutions of this dye. Adsorption of this dye over limestone surface was investigated under different adsorption conditions such as study the effect of contact time, mass of the used adsorbent, effect of temperature and $\mathrm{pH}$ of reaction mixture. From the obtained results it was found that the optimum adsorption conditions were using $0.2 \mathrm{~g}$ of the adsorbent, temperature was $35^{\circ} \mathrm{C}$, and $\mathrm{pH}=7$.
\end{abstract}

Keywords: Maxlion Blue GRL dy, powdered limestone, adsorption processes

\section{Introduction}

In the last few years and due to high levels of pollution that are produced from mass applications of modern industrial products in our current life such as food, pigments, medicines, clothes, dying processes and many other applications. The use of these materials leads to increase levels of pollution in our environment at each of water, air and soil. Generally, there are different sources of pollutants in our modern life and probably important source among them are the textile industries. It is well known that, this type of industry use wide range of synthetic dyes that are used in different processes especially in dying processes $[1,2]$. These dyes have a complex aromatic structure that is can't be fragmented easily under normal conditions. Most of these dyes are eluted to industrial waters that are discharged from textile factories into the nearest water stream such as rivers, lakes and to the normal soil. Most of these dyes have a deep color and are polluted and toxic for all living organisms. In addition to that, these dyes can participate in other reactions and yield carcinogenic and/or toxic secondary products.

In some cases some of these polluted dyes are effluent to the sources of drinking water and this case can produce big problem [3,4]. The big difficulty in treatment of polluted dyes in the textile wastewaters is coming from the high resistance of these dyes for decomposition and/or fragmentation when are subjected to normal treatment conditions such as using normal air conditions, industrial light, sunlight and/ or chemical oxidizing agents $[5,6]$.

In this context, different methods can be applied in treatment of textile industrial wastewaters such as physical, chemical and biological treatment seems to be not efficient with these dyes due to the above mentioned reasons $[7,8] . I n$ last few decades, adsorption processes were a promising alternative route that can be used more efficiently in dye removal in comparison with the above methods. These methods can give a high removal efficiency and relatively low cost with easily[9]. However, in this type of treatment adsorbent is the principal factor so that its general physical and chemical properties can play important role in this process.
Limestone is a widely available sedimentary rock, it is composed of minerals calcite and aragonite with a different crystal forms of calcium carbonate $\left(\mathrm{CaCO}_{3}\right)$. Most of these stones are composed of skeletal fragments of marine organisms such as coral, forams and molluscs.

Limestone contains around $10 \%$ of the total volume of all sedimentary rocks. It has a solubility of limestone in water and weak acid solutions leads to karst landscapes, in which water erodes the limestone over thousands to millions of years. Most cave systems are through limestone bedrock. This type of stones can be used as adsorbent for wide spectrum of adsorbates due to high porosity which enable it to show high efficiency towards adsorption of many types of dyes and other adsorbents.

The present study, investigates adsorption of maxlion blue GRL dye (MBGRL) over the surface of limestone using simulated aqueous solutions of this dye. Different adsorption conditions would be undertaken in this work.

\section{Experimental Part}

\subsection{Adsorbate}

The MaxilonBlue dye (GRL), was provided by Al-Hilla textile factory in Babylon/IRAQ. It has a molecular formula $\mathrm{Mf}:\left(\mathrm{C}_{20} \mathrm{H}_{26} \mathrm{~N}_{4} \mathrm{O}_{6} \mathrm{~S}_{2}\right)$ and has a molecular weight (Mw:482.52 $\mathrm{g} / \mathrm{mol})$.

\subsection{Adsorbent}

Limestone is a sedimentary rock composed largely of the minerals calcite and aragonite, which are different crystal forms of calcium carbonate $(\mathrm{CaCO} 3)$. Most limestone is composed of skeletal fragments of marine organisms such as coral, forams and molluscs.

The adsorbent was prepared by taking the lime rock and then it was grinded finely and then passed through a molecular sieves $(100 \mu \mathrm{m})$. The obtained powder then washed with $\mathrm{HCl}(0.1 \mathrm{M})$ for some times, and then it was dried at $115^{\circ} \mathrm{C}$ in oven for 24 hour. The final obtained powder then would be used in 


\section{International Journal of Science and Research (IJSR) \\ ISSN (Online): 2319-7064}

Index Copernicus Value (2013): 6.14 | Impact Factor (2014): 5.611

adsorption processes for the used model of textile dye Maxlion Blue GRL dye.

\subsection{Adsorption Studies}

In this study, adsorption processes were carried out under normal atmospheric conditions using a magnetic stirrer. Initial dye concentration was $20 \mathrm{ppm}$. In each experiment a simulated sample of industrial wastewater containing a dye concentration of $20 \mathrm{ppm}$ in $100 \mathrm{~mL}$. To this solution the used lime stone powder $0.2 \mathrm{~g}$ was loaded and the mixture was kept under stirring under air. In all experiments, periodically $2 \mathrm{~mL}$ of the reaction mixture was withdrawn for each ten minutes and for duration of one hour of reaction time. These samples then were centrifuged for several times and the absorbance was systematically recorded at a wavelength of $610 \mathrm{~nm}$. The absorbance of the supernatant liquid was recorded using Spectrophotometer Shimadzu 1650 PC-UV-visible. The efficiency for dye removal from the simulated industrial wastewaters $(\mathrm{R} \%)$ was calculated using the following equation $[10,11]$ :

$$
R \%=\frac{C_{i}-C_{f}}{C_{i}} \times 100
$$

Where, $C_{i}$ is the initial dye concentration and $C_{f}$ is the final dye concentration that is remaining after one hour of adsorption

\subsection{Effect of Time Loaded on Dye Removal}

The effect of lime stone dosages and contact time on dye removal were conducted by performing a series of experiment, in each one an aqueous solution of MBGRL(20 ppm, $100 \mathrm{~mL})$ was used. These experiments were undertaken at different contact times that are ranged from (0-60) minutes. To investigate the effect of mass of lime stone on the dye removal, different dosages of lime stone were used.

\subsection{Effect of Temperature on Dye Removal}

To study effect of temperature on adsorption of MBGRL dye, a series of experiment were performed. In each experiment $0.2 \mathrm{~g}$ of powder was suspended in $100 \mathrm{ml}$ of dye solution $20 \mathrm{ppm}$. Adsorption was performed at three different temperatures $35,45,50$, and $60^{\circ} \mathrm{C}$. The amount of dye that is remaining in solution was followed spectrophotometrically by measuring optical density at $610 \mathrm{~nm}$.

\subsection{Effect of pH on Adsorption}

In order to investigate the effect of the $\mathrm{pHs}$ of the reaction mixture on the removal of Maxilon dye from the used aqueous solution. A series of experiments were performed under different values of $\mathrm{pH}$. The $\mathrm{pH}$ of mixture was adjusted to a desired value by adding small droplets from $0.1 \mathrm{~N} \mathrm{HCl}$ and $\mathrm{NaOH}$ to the initial aqueous solutions with using $\mathrm{pH}$ meter measurement to adjust the $\mathrm{pHs}$ to precise values.

\section{Results and Discussion}

\subsection{Effect of weight of adsorbent and contact time on dye removal}

To study the effect of lime stone loaded on dye removal a series of experiment were performed using different loaded masses of the used lime stone and applying the same adsorption process. From the obtained results it was found that there was enhancement on dye removal with increase the amount of the adsorbent. This may arise from increase the amount if the available adsorption sites and increase of the effective surface area of the used lime with increase of the amount of lime. This can lead to increase adsorption capacity of lime stone with increase of mass loaded[12]. These results are presented in Figure 1.

The effect of contact time on dye removal was investigated by performing adsorption process of MBGRLdye over limestone over two hours. The obtained results are presented in Figure 1.as absorbance of dye against time. From these results it is clear that the efficiency of dye removal was enhanced with increase of time[13]. This can be attributed to increase adsorption capacity with the development of time. After two hours there was stability in adsorption profile this probably due to reach adsorption equilibrium and fill all adsorption sites of lime stone surface.

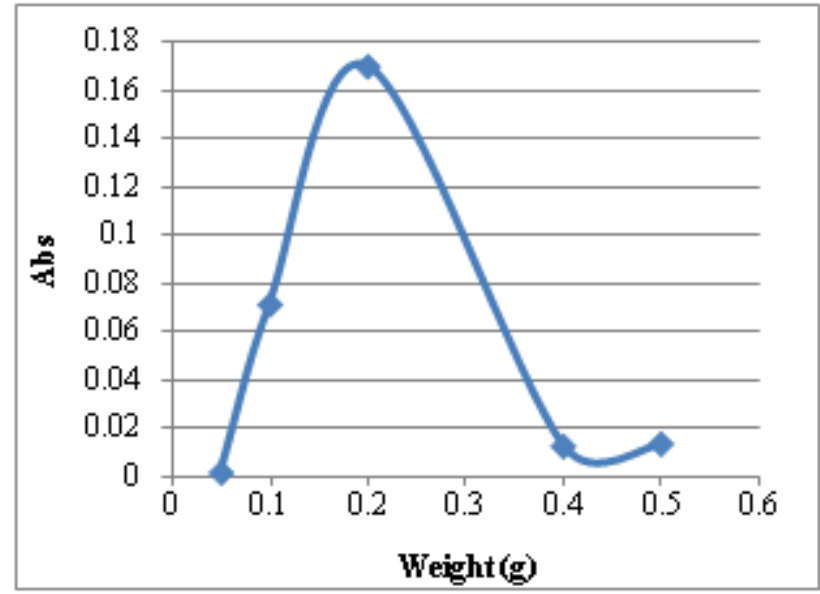

Figure 1: Effect of weight of lime stone on removal of MBGRL dye over lime stone surface

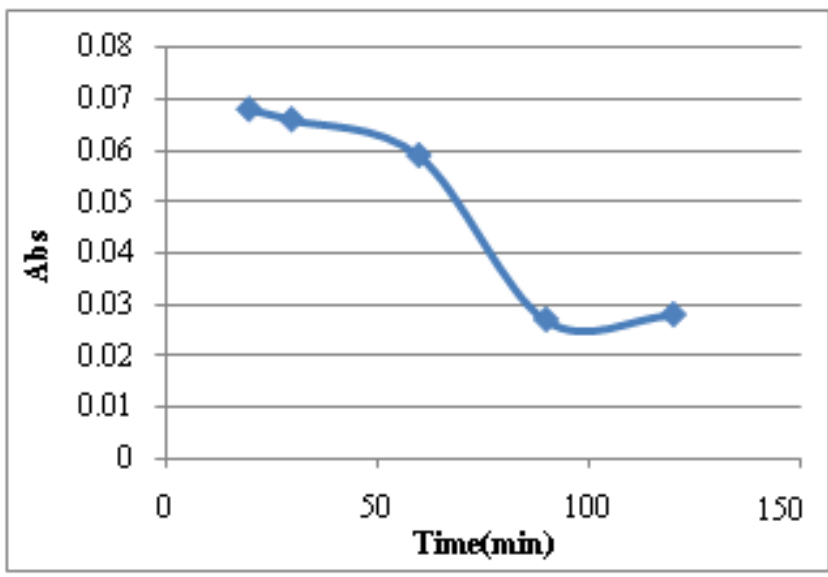

Figure 2: Effect of contact time on MBGRL dye removal over lime stone surface 


\subsection{Effect of temperature on dye removal over lime stone}

The effect of temperature on adsorption of MBGRL dye over lime stone was investigated over a range of temperature. The obtained results are presented in Figure 3 as a lnk against $1 / \mathrm{T}(\mathrm{K})$. These results showed that the efficiency of dye removal was decreased with increase of temperature[14, 15]. The optimum efficiency of dye removal was obtained at $35 \mathrm{C}$ while higher temperature gave negative results. This probably arises from the exothermic nature of adsorption process, so that according to Lech at lee principle adsorption efficiency decreases with increase of temperature.

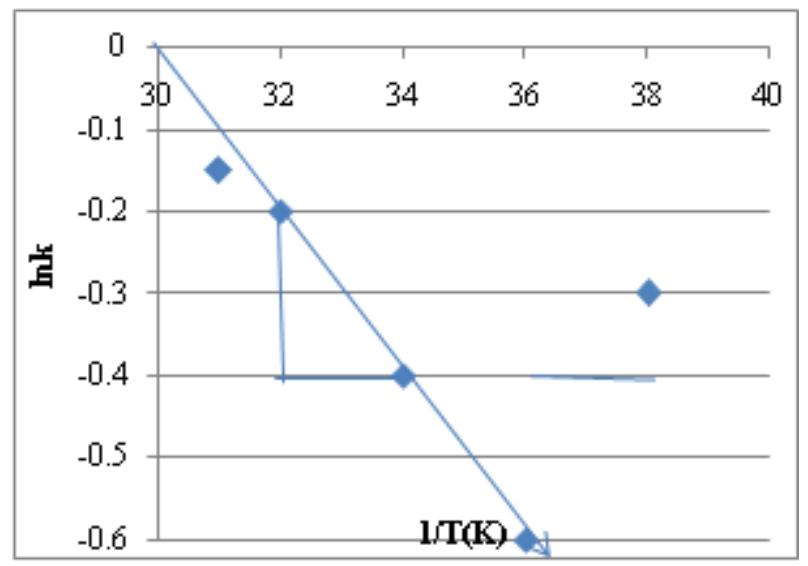

Figure 3: Effect of temperature on MBGRLdye removal over lime stone surface

\subsection{Effect of $\mathrm{pH}$ of reaction mixture on dye removal}

The effect of $\mathrm{pH}$ of reaction mixture on dye removal was investigated via performing adsorption processes at different $\mathrm{pHs}$ values from 2-14.The obtained results are presented in Figure 4, and the results are presented as optical density against $\mathrm{pH}$ value. The best result was achieved at neutral medium $(\mathrm{pH}=7.0)$, this arises from repulsion forces that present in case of acidic $(7>\mathrm{pH})$ and basic medium ( $\mathrm{pH}>7)$. In case of neutral $\mathrm{pH}$ medium $(\mathrm{pH}=7)$ it believe that no repulsion forces between dye molecules and lime stone surface $[16,17]$.

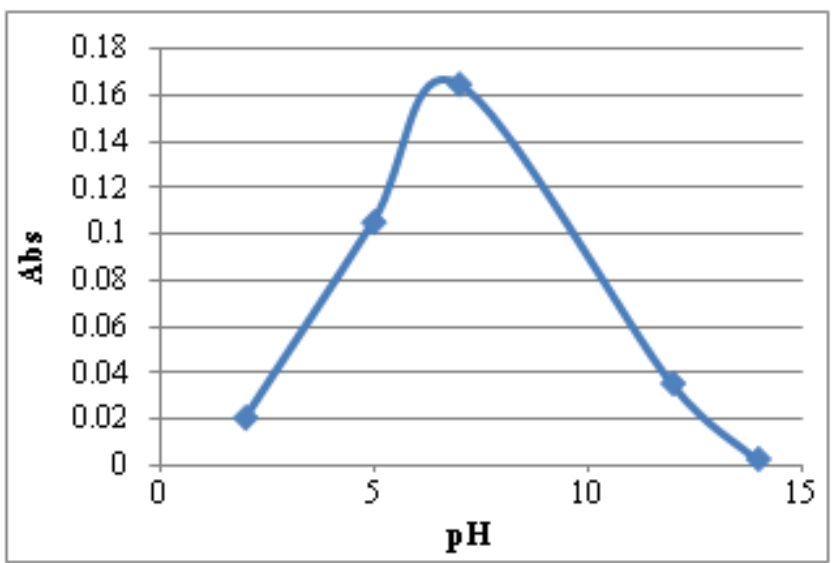

Figure 4: Effect of $\mathrm{pH}$ of reaction mixture on removal of MBGRL dye over lime stone surface

\section{Conclusions}

In the present study lime stone was used effectively on removal of MBGRL textile dye from its simulated wastewater. This material was used as an adsorbent surface to remove of this dye from its aqueous solution. Removal efficiency of this dye over lime stone was increased with increase of the amount of used lime stone and with increase of contact time. Increasing of adsorption temperature leads to reduce the efficiency of dye removal. In terms of $\mathrm{pH}$, neutral medium gave higher removal efficiency in comparison with acidic and basic medium.

\section{References}

[1] M. Hoffmann, S. Martin, W. Choi and D. Chemical Reviews, 1995, 95(1), 69-96.

[2] U. Siemon, D. Bahnemann, J. Testa, D. Rodr, M. Litter and N. Bruno, Journal of Photochemistry and Photobiology A: Chemistry, 2002, 148(1-3), 247-255.

[3] T. Budinova, E. Ekinci, F. Yardim, A. Grimm, E. Bjornbom, V. Minkova, and M. Goranova. Fuel Process. Technolo, 2006, 87, 899-905.

[4] M. Ali and R. Streekrishnan. Adv. Environ. Res., 2001, 5, 175-196.

[5] I. Chenotang, X. Hui, L. Huaming, L. Ling, X.Li and Y. Zhixiang. Korean J. Chem. Eng 2011, 28 (4), 1126-1132.

[6] T. Robinson, G. McMullan, R. Manchant and P. Nigam. Bioresour. Technol 2001, 77(3), 247-255.

[7] G. Muthurman, T. Teng, C. Lech and I. Norli. J. Hazard. Mater 2009, 163(1), 363-369.

[8] I. Fatimah, S. Wang and D. Wulandri. Appl. Clay Sci., 2011, 53(4), 553- 560.

[9] G. Criniand P. Badot, Progress in Polymer Science, 2008, 33 (4), 399-447.

[10] A. Lafta, A. Halbus, Z. Athab, A. Kamil, A. Hussein, A. Qhat and F. Hussein. Asian Journal of Chemistry, 2014, 26, 119-123.

[11]F. Hussein, A. Halbus and Z. Athab. Int. J. Chem. Science, 2013, 11(3), 1219-1233.

[12] R. Katal, M. Bae, H. Rahmati and H. Esfandian., J. Indus. Eng. Chem., 2012, 18(1), 295-302.

[13]F. Pavan, E. Lima, S. Dias and A. Mazzocato. Journal of Hazardous Materials, 2008, 150 (3), 703-712.

[14] A. Sepulveda and C. Santana, Environ. Technol., 2013; 34(5-8), 967-77.

[15] Y. Al-Degs, M. El-Barghouthi, A. El-Sheik and G. Walker, Dyes and Pigments, 2007, 77(1), 16-23.

[16] K. Ramakrishna and T. Viraraghavan. Waste Management 1997, 17(8), 483-488.

[17] O. Yavus, Y. Altunkaynak and F. Guzel. Water Res 2003, 37(4), 948-952. 